\title{
ENVOLVIMENTO DOS PAIS: INCENTIVO À HABILIDADE DE ESTUDO EM CRIANÇAS
}

\author{
PARENTS INVOLVEMENT: \\ MOTIVATING CHILDREN STUDY SKILLS
}

\author{
Maria Rita Zoéga SOARES ${ }^{1}$ \\ Sílvia Regina de SOUZA ${ }^{1}$ \\ Maria Luiza MARINHO ${ }^{1}$
}

\begin{abstract}
RESUMO
Psicólogos têm sido solicitados a oferecer orientação a pais sobre a influência de suas atitudes no desempenho acadêmico dos filhos. Tanto a escola quanto a família são instituições importantes à socialização e à educação infantil e há efeitos positivos relacionados ao envolvimento parental na vida acadêmica das crianças. Orientações deveriam ser fornecidas no sentido de prevenir problemas comportamentais, facilitando a interação dos pais na realização dos trabalhos escolares dos filhos, utilizando o encorajamento verbal e o reforço direto, o que supõe suporte e monitoramento das atividades diárias e do progresso escolar. O envolvimento dos pais na vida acadêmica dos filhos deve ser incentivado devido aos benefícios que pode trazer para o sucesso acadêmico. O objetivo do presente artigo foi o de apresentar orientações para que pais promovam o desenvolvimento de comportamentos facilitadores da aprendizagem e possam participar mais ativamente da vida acadêmica dos filhos.
\end{abstract}

Palavras-chave: crianças; pais; orientação educacional; relações familiares; hábito de leitura.

\begin{abstract}
Psychologists have been requested to offer parents guidance, regarding the influence of their attitudes on their children academic performance. Both school and family are considered important institutions for the children socialization and education, and there are positive effects on the parents'
\end{abstract}

\footnotetext{
${ }^{1}$ Departamento de Psicologia Geral e Análise do Comportamento, Universidade Estadual de Londrina. Rod. Celso Garcia Cid - PR445, km 380, Campus Universitário, 86051-990, Londrina, PR, Brasil. Correspondência para/Correspondence to: M.R.Z. SOARES.
} 


\begin{abstract}
involvement in academic life of their children. The parents guidance should avoid behavioral problems, providing parents participation on their children academic activities through motivation and feedback, that implies children assistance and monitoring of their daily activities and academic process. The parents involvement with their children academic life must be motivated as it can provide benefits to academic success/led to the academic success. Guidelines focused on the development of learning facilitating behaviors were the purpose of this present study in order to promote an achieve parents participation on their children academic life.
\end{abstract}

Key-words: children; parents; educational counseling; family relation; reading habits.

As transformações vividas por nossa sociedade conduziram a mudanças na forma de interagir com as crianças. Algumas práticas educativas já validadas passaram a ser questionadas e atualmente restam muitas dúvidas sobre como proceder com relação à educação dos filhos (Biasoli-Alves, 1997). Orientações sobre fatores correlacionados ao desenvolvimento de crianças têm sido dadas aos pais com a finalidade de prevenir problemas comportamentais infantis em diferentes contextos (Marinho, 2001).

Em relação ao comportamento infantil no contexto escolar, pesquisadores destacam os efeitos positivos do envolvimento dos pais na vida acadêmica dos filhos (Cooper, Lindsay \& Nye, 1999; Marturano, 1999; Souza, 2000). Envolvimento parental diz respeito às interações dos pais na realização dos trabalhos escolares dos filhos e ao encorajamento verbal e de reforço direto de comportamentos que produzam melhora no desempenho acadêmico, o que supõe suporte e monitoramento das atividades diárias e do progresso escolar (Ferhaman, Keith \& Reimers, 1987). Além disso, o envolvimento pode abranger idas à escola e participação em reuniões diversas e em discussões sobre questões relacionadas ao ambiente familiar (por exemplo, possibilitar à criança o acesso a materiais escolares e a local apropriado para estudo).

Uma vez que tanto a escola quanto a família são instituições importantes à socialização e à educação infantil (Grolnick \& Slowiaczek, 1994), é compreensível que os comprovados efeitos positivos do envolvimento parental na vida escolar dos filhos incentivem as escolas a solicitarem dos pais uma participação mais efetiva. Entretanto, a exigência por parte da escola e a ausência de procedimentos e de orientações claras que viabilizem uma interação produtiva entre ambas as instituições têm resultado em contatos conflitivos entre pais e profissionais de instituições de ensino.

Há alguns fatores que parecem dificultar que os pais participem ativamente da vida escolar de seus filhos. Dentre eles, pode-se citar: as mudanças nas práticas de ensino; o desconhecimento dos assuntos trabalhados na escola; a falta de tempo, em especial para pais que trabaIham fora; o nível de dificuldade de aprendizagem apresentado pelos filhos; o tipo de avaliação feita pela escola; os comportamentos gerais dos profissionais da escola em relação aos pais e às crianças; o desconhecimento de como proceder para enfrentar problemas relacionados à vida acadêmica dos filhos etc.

Problemas de desempenho ou de comportamento na escola são uma das causas mais comuns de estresse para pais e filhos. Em geral, o nível de estresse é diretamente proporcional à freqüência de cobranças de intervenção feitas pela escola, ao tipo de acusações, assim como ao acesso ou não a informações concedidas aos pais sobre como proceder. Algumas conseqüências desse quadro são a esquiva em ir à escola e em envolver-se nas atividades escolares dos filhos. 
Sem orientação adequada e com pouco tempo, alguns pais acabam usando de práticas coercivas (agressões físicas e castigos) para tentar mudar o comportamento da criança em relação aos estudos. De acordo com Hübner e Marinotti (2000), essas dificuldades, aliadas à baixa freqüência de comportamentos infantis reforçados (já que a probabilidade de comportamentos adequados nessa situação pode ser baixa), podem gerar comportamentos infantis de esquiva e de fuga da situação. As crianças, portanto, podem se recusar a ir à escola, podem mentir dizendo que não têm tarefa de casa etc. Os pais, então, podem castigá-las por seu comportamento e um novo ciclo se inicia. Nesses casos, as autoras afirmam que mudanças em contingências familiares e suporte pedagógico podem ser necessários.

O envolvimento dos pais na vida acadêmica dos filhos é um aspecto que deve ser incentivado porque pode promover condições favorecedoras para a aprendizagem. É necessário descrever quais atitudes os pais devem tomar para auxiliarem seus filhos a realizar tais tarefas.

Sendo assim, este artigo tem a finalidade de apresentar 14 orientações para que os pais promovam o desenvolvimento de comportamentos facilitadores da aprendizagem e possam participar mais ativamente da vida acadêmica dos filhos.

\section{ORIENTAÇÕES PARA A PROMOÇÃO DE COMPORTAMENTOS FACILITADORES DA APRENDIZAGEM EM CRIANÇAS}

\section{1) Tornar explícitos os deveres e os direitos dos filhos}

Deve ser ensinado, aos filhos, desde pequenos, que eles têm direitos e deveres. Uns não existem independentemente dos outros, pois estão relacionados.

Alguns direitos o indivíduo tem pelo simples fato de pertencer à espécie humana. Alguns exemplos são os direitos a receber afeto, carinho, proteção, alimento, cuidado, que devem ser aten- didos incondicionalmente pelos pais. O amor deve ser incondicional (Marinho, 2001).

Há, por outra parte, direitos que são adquiridos, em geral, após o cumprimento de alguns deveres ou sob certas condições. Assim, cumpridos os direitos básicos e incondicionais dos filhos, os pais devem deixar claramente especificados quais são os seus deveres e direitos. No caso de não se cumprir um dever, não se pode usufruir o direito relacionado. Por exemplo, a criança pode ter como dever fazer suas tarefas escolares. Depois disso, terá direito de ligar a TV. Se não cumpre seu dever, não pode usufruir o direito. Se os pais estabelecem essas normas e exigem seu cumprimento incondicional (nunca poderá ver TV sem antes ter feito as tarefas escolares), observarão que a criança apresentará comportamento responsável. Isso contribui, por exemplo, para que os filhos se responsabilizem pela realização de suas tarefas escolares.

\section{2) Estabelecer uma rotina organizada}

Rotina se refere aos horários definidos para a realização das diversas atividades que a criança deve cumprir a cada dia. Sua organização supõe a distribuição dos horários para os estudos. Assim, é importante que os horários estejam claramente estabelecidos: hora de ir à escola, de comer, de estudar em casa, de realizar atividades como brincar e assistir à TV etc. A agenda diária e semanal deve estar sempre disponível para ser consultada pela criança: um cartaz grande e colorido em geral é uma boa estratégia.

Os pais devem consultar a criança e, se necessário, os professores, para obter informações sobre as atividades, sua freqüência e duração. Somente com dados claros e precisos poderão compor uma rotina adequada e possível de ser cumprida sem estresse. Os finais de semana também devem ser incluídos na agenda, tomando-se o cuidado para que haja períodos longos em que a criança possa ter liberdade para escolher que atividade realizar.

Uma questão relevante na definição dos horários é que os pais demonstrem que os estudos são uma das atividades prioritárias e o 
tempo para tal condição deve ser respeitado. A realização das atividades escolares deve vir sempre em primeiro lugar para evitar que a criança a adie para quando estiver cansada. Entretanto, os pais devem permitir que a criança também faça o que gosta (brincar, divertir-se com o computador, praticar esporte etc.), mas tais atividades devem ser deixadas para depois da realização das tarefas escolares (a questão dos direitos e deveres).

Sempre que possível, deve-se incentivar a convivência familiar durante as refeições, as atividades escolares, ao assistir à TV etc. Esses momentos passados juntos devem ser prazerosos. Ficar fisicamente próximo à criança durante seus momentos de estudo em casa (seja para auxiliá-la nas tarefas ou para apoiá-la) contribui para que o horário de estudos seja agradável e não solitário.

As crianças aprendem muito rapidamente observando os adultos. Se os pais estabelecem também uma rotina para si, deixam-na exposta (em um cartaz, por exemplo) e a cumprem, poderão ajudar seus filhos servindo como modelo de responsabilidade e autocontrole. Além disso, crianças que vêem seus pais lendo ou realizando atividades similares às atividades escolares (ler, escrever, estudar etc.) aprendem que essas são valorizadas pela família e passam a valorizá-las também.

Uma agenda sobrecarregada de atividades é uma condição que dificulta o estabelecimento de uma rotina infantil saudável. Atividades como aula de dança, de inglês, de música etc. devem ser motivadoras para a criança e não uma carga imposta. Para tanto, os pais devem envolvê-la na escolha de atividades opcionais, incentivá-la e devem participar e respeitar suas escolhas. A criança tem o direito de poder errar ao fazer sua opção, pois o momento de errar é esse; assim ela poderá descobrir o que mais gosta de fazer.

\section{3) Estabelecer limites}

Crianças devem ser ensinadas a conviver em sociedade e necessitam de normas de conduta claras. Não permitam os pais que elas ditem as regras da casa. Quando têm um tempo disponível para o filho e são afetuosos, os pais têm maior probabilidade de se sentirem seguros e tranqüilos para delimitar tais regras. A criança sem parâmetros fica desafiando os adultos até conseguir ouvir um basta de pais já irritados e exaustos. Nessa situação, os pais tendem a ser muito mais punitivos e severos. A autoridade deve ser exercida sem autoritarismo e a última palavra deve ser sempre dos pais.

Devem, também, ser respeitados os limites físicos, intelectuais, sociais e emocionais da criança. A prática de atividades extracurriculares pode dar oportunidade ao indivíduo de se sentir competente e valorizado e tal condição pode-se generalizar para a escola. A criança que se sente mais competente melhora seu autoconceito e sua auto-estima.

\section{4) Supervisionar atividades}

Quanto mais nova a criança, maior a necessidade de supervisão de suas atividades. Pesquisas afirmam que o progresso na aprendizagem escolar está relacionado à supervisão e à organização das rotinas do lar (Marturano, 1999). Supervisionar inclui verificar se a criança está cumprindo os horários da rotina e orientá-la na execução das tarefas. A criança não pode se sentir abandonada. Embora necessite que o adulto a oriente, é inaceitável que os adultos façam as atividades por ela. Quando os pais fazem os deveres escolares de seus filhos, estes geralmente se sentem incapazes.

Outro aspecto a ser ressaltado é que a participação em atividades escolares não deve ser uma tarefa só de mães. É fundamental que também o homem assuma esse papel como uma oportunidade de interação com os filhos e como modelo de envolvimento no estudo.

\section{5) Dosar adequadamente proteção e incentivo à independência}

As antagônicas atitudes de superproteção e de permissiva independência podem prejudicar o desenvolvimento emocional e cognitivo da 
criança. Ela deve aprender a ser independente, mas sem se sentir abandonada. Para isso, os pais devem conciliar o supervisionar com o conceder independência gradativa ao filho.

Esse não é um limite fácil de ser estabelecido. Há pais que persistem no controle e nas ordens, mesmo quando os filhos já demonstram habilidade para tomar iniciativa para o estudo. Uma opção é ensinar à criança o processo para chegar às respostas. Pais não precisam ser um poço de conhecimento, mas um modelo de responsabilidade (Hübner, 1999).

Dessa forma, é importante aprender a observar a criança, avaliar suas capacidades, suas preferências e seu ritmo, que devem, na medida do possível, ser respeitados. Os pais devem avaliar que atividades são realmente importantes para a criança a fim de organizarem uma agenda que a deixe realmente feliz, sem excessos de obrigações não condizentes com sua idade e interesses.

\section{6) Prover um ambiente com recursos e instrumentos para estudar}

É necessário dispor um ambiente adequado para o estudo, possibilitando um espaço físico sem distrações, com pouco ruído, arejado, iluminado e organizado. Deixar acessível o material necessário para a realização das tarefas escolares, além de demonstrar disponibilidade para consulta ou para pedidos de ajuda em caso de dúvidas. É importante que a harmonia e a tranqüilidade também estejam presentes. Um ambiente caótico não promove a educação.

Como Hübner (1999) explicita, quando os pais respondem a esses requisitos com boa vontade, criam um ambiente que ajuda a criança a perceber que as tarefas escolares devem ser cumpridas e que o estudo é valorizado.

\section{7) Estabelecer interações positivas}

O castigo é uma estratégia geralmente utilizada pelos pais para que a criança pare de realizar um comportamento inadequado. Mas há dois aspectos relevantes a serem destacados: a) fazer com que a criança pare de apresentar um comportamento não a leva, necessariamente, a contrapor um comportamento adequado (p. ex., a criança pode parar de fazer algazarra e, ainda assim, não começar a estudar); b) castigos, em geral, funcionam durante curtos períodos de tempo (os pais sabem que as crianças voltam a apresentar, na maioria dos casos, comportamentos que Ihes mereceram castigo anteriormente).

Então, o uso de sistemas aversivos de controle como castigos, retiradas de privilégios, broncas, sermões e humilhação não contribuem para que a criança passe a apresentar um comportamento adequado (por exemplo, ser responsável, realizar as tarefas escolares etc.). Além disso, castigos relacionados a questões escolares contribuem, a médio prazo, para produzir falta de interesse por assuntos da escola (não querer fazer o dever de casa, simular doenças para não ir à escola, não prestar atenção no que está sendo ensinado etc.).

Dessa forma, os pais devem estabelecer condições que propiciem comportamentos considerados relevantes para a educação de seus filhos. A criança não nasce responsável, mas aprende a se comportar responsavelmente. A forma adequada de conseguir esses resultados é criar condições para que a criança tenha o comportamento adequado, por exemplo, acompanhála à mesa de estudos, apresentar recompensas imediatas quando o comportamento adequado ocorrer ("Está legal nós dois aqui estudando juntos"); especificar porque ela está sendo recompensada ("Você está se esforçando pra valer!"), o que contribui para fortalecer os comportamentos adequados (Marinho, 2001). Além disso, o incentivo, o estabelecimento claro de limites, instruções e uma disposição para fornecer dicas eficientes aumentam o interesse e a satisfação das crianças pelos estudos. Elogios sinceros, imediatos e contextuais relacionados às respostas da criança aumentam a probabilidade do comportamento de estudar (Hübner, 1999). Portanto, os pais devem elogiar sempre o empenho em qualquer atividade. Qualquer criança precisa de palavras de afirmação e de encorajamento por seu envolvimento nas tarefas. 
No entanto, quando se trata de elogio, um cuidado é necessário: ao elogiar, os pais não devem criticar nem propor desafios ou metas superiores. "Estamos contentes com isso que você fez. Você poderia fazer assim sempre!" - é um exemplo de elogio seguido de crítica. "Que legal filho! Vamos ver se na próxima vez você consegue um 10!" - é um exemplo de elogio seguido de desafio. Isso causa ressentimento e a criança pensará que ela não é boa o bastante (Marinho, 2002). Os pais devem fazer os filhos acreditarem em suas possibilidades, verbalizando que eles são capazes, e devem, também, apontar as habilidades. Verbalizações encorajadoras são de fundamental importância.

Outra questão importante é que, ao demonstrar a evolução da criança em termos de desempenho, os pais devem fazê-lo comparandoa com seus próprios resultados anteriores e nunca com o de outra criança; a própria criança deve ser o ponto de referência para si mesma.

Por último, em relação ao estabelecimento de interações positivas, os pais devem evitar o uso de dinheiro, presentes caros, ou ameaças (retirada da viagem de férias etc.) para conseguir o que desejam. Presentear a criança com livros, revistas e materiais (papel, canetinhas coloridas, argila, tinta etc.) que agucem sua curiosidade é uma estratégia adicional mais positiva.

\section{8) Demonstrar afeto}

Reforçar positivamente o comportamento é uma forma de possibilitar o desenvolvimento da auto-estima. Guilhardi (1998) afirma que a auto-estima se desenvolve a partir do amor genuíno. Amor genuíno é definido como a capacidade de amar mesmo na adversidade. Para o autor, a criança precisa sentir que é amada na vitória e na derrota com a mesma intensidade. Demonstrar que sente prazer pelo que a outra pessoa fez ou que está contente com a sua presença é reforçar o comportamento daquele a quem se ama (Skinner,1991).

Atualmente, fala-se muito em afeto, mas valoriza-se o desempenho (produção e competência). A disciplina e o estabelecimento de limites e de regras só são efetivos quando os pais demonstram amor pelos filhos. Tal demonstração deve ser feita através da organização de um tempo para desenvolver atividades com eles e expressar seu amor por eles, através de atos e palavras. As atividades escolares podem ser uma oportunidade para a demonstração de afeto a que se acrescenta a conscientização da necessidade de trabalhar aspectos cognitivos, afetivos, sociais e físicos. Atualmente, sabe-se que para o desenvolvimento cognitivo é necessário que as demais áreas também se desenvolvam.

\section{9) Ser modelo adequado de envolvimento com as atividades}

Os exemplos mais eficazes são apresentados através de atos e não de palavras. Os pais podem instruir e/ou funcionar como modelos. A criança vai fazer o que você faz e não o que você diz.

A esse respeito, Skinner (1991) comenta que dizer e mostrar são maneiras de incitar comportamentos, de levar as pessoas a se comportarem de uma dada maneira pela primeira vez, e de modo que se possa reforçar-Ihes o comportamento. Comenta que a modelação (aprendizagem através da observação do comportamento de um modelo) é uma forma de ensino e a permanência de seu efeito depende do reforço. Quando ocorrem conseqüências reforçadoras, nós aprendemos.

Para incentivar a leitura, até descobrir o que o filho gosta de ler, pais podem, inicialmente, escolher livros que eles próprios apreciavam quando crianças. O hábito de ler pode ser facilitado com a escolha de um momento, a cada dia, para a leitura conjunta de um livro. Os pais devem demonstrar seu entusiasmo durante a atividade porque a criança vai observar sua atitude na atividade. Deve-se solicitar que a criança também escolha suas leituras e as faça para os pais.

\section{0) Promover diálogo}

Os pais devem estar disponíveis para que a criança tenha liberdade e vontade de procurá-los 
para conversar e esclarecer dúvidas. Cuidado para que esses momentos não se transformem em monólogos em que os pais apenas questionam, pois isso desestimula a criança. Os pais devem aproveitar esses momentos para também se expressar, contar sobre sua rotina e sua vida, e devem considerar apenas os assuntos de interesse e de capacidade de compreensão da criança. Assuntos de adultos devem ser discutidos com adultos.

\section{1) Apresentar nível de exigência compatível com o desempenho da criança}

Qualquer pai bem intencionado fica ansioso para que o filho tenha um bom desempenho na escola e cumpra suas expectativas. Altos níveis de exigência podem gerar um grau elevado de frustração e um índice maior de desistência e de perda de interesse. Não se deve pensar só em resultados numéricos, mas em auto-estima, em autoconfiança, em relacionamento interpessoal, em capacidade de relaxar, em momentos para brincar. Se os pais não souberem valorizar essas situações, não saberão como incentivar os filhos.

\section{2) Relacionar o teórico com a prática}

Os pais devem valorizar o que a criança está aprendendo, relacionando o conteúdo com suas experiências. Pode-se aprender conceitos valiosos através da administração da mesada (matemática), viagens e mapas (geografia), leitura sobre o local, assuntos de interesse em revistas (português). Aprender deve ser por si só uma atividade reforçadora.

\section{3) Incentivar o brincar}

O dia-a-dia da criança não deve ser transformado num fazer contínuo. Deve haver períodos para brincar livremente e espaço para descontrair e relaxar. O brincar também favorece o bom desempenho escolar (aquisição de habilidades), melhora a concentração e a autoconfiança. A criança que brinca tem menos problemas educacionais e emocionais (Bomtempo, 1997; Soares, 2002).

\section{4) Interessar-se pela vida do filho}

Os pais devem demonstrar interesse pelas atividades da criança não apenas quando as coisas não dão certo (notas baixas, brigas com os colegas, isolamento etc.). Devem participar de reuniões e atividades comemorativas que a escola organiza, demonstrando que valoriza o seu mundo acadêmico. É preciso que a escola e a família sejam parceiras; a escola pouco pode fazer sem o auxílio e a participação direta dos pais. Educar não se reduz à transmissão de conteúdos; educar é preparar para a vida, para seus desafios e para a realização pessoal.

\section{CONSIDERAÇÕES FINAIS}

A opção de ter filhos envolve mais do que a sua geração. $O$ bebê exige anos de dedicação por parte dos adultos até que possa ser um adulto autônomo. O desenvolvimento cognitivo infantil é tarefa compartilhada entre duas grandes instituições da nossa sociedade: a família e a escola.

Embora atualmente a maioria dos pais trabalhe fora e tenha pouco tempo disponível para a vida doméstica, as necessidades referentes ao adequado desenvolvimento das crianças continuam as mesmas: dedicação, afeto, estimulação, experiências diversas etc. Parte dessas responsabilidades não pode ser atribuída à escola, e não apenas em razão de dificuldades estruturais, mas porque algumas responsabilidades não podem ser transferidas de um contexto ao outro. Dessa forma, a maioria das orientações dadas aqui é de suma importância para o desenvolvimento integral da criança e deve ser incluída na rotina da família, persistentemente, no dia-a-dia, e com total envolvimento.

\section{REFERÊNCIAS}

Biasoli-Alves, Z.M.M. (1997). Contribuições da psicologia ao cotidiano da escola: necessárias e adequadas? Paidéia, 12 (13), 77-95. 
Bomtempo, E. (1997). Brincando se aprende: uma trajetória de produção científica. Trabalho de Livre-Docência. Instituto de Psicologia, Universidade de São Paulo.

Cooper, H., Lindsay, J.J., \& Nye, B. (1999). Homework in the home: How student, family, and parenting-style differences relate to the homework process. Contemporary Educational Psychology, 25, 464-487.

Ferhamann, P.G., Keith, T.Z., \& Reimers, T.M. (1987). Home influence on school learning: Direct and indirect effects of parental involvement on high school grades. Journal of Educational Research, 80, 330-337.

Grolnick, W., \& Slowiaczek, M.L. (1994). Parent's involvement in children's schooling: A multidimensional conceptualization and motivational model. Child Development, 65, 237-252.

Guilhardi, H.J. (1998, 20 de novembro). Reflexos da infância. Folha de Londrina.

Hübner, M.M. (1999). Contingência e regras familiares que minimizam problemas de estudo: a família pró-saber. In R.R. Kerbauy \& R.C. Wielenska (Orgs.). Sobre Comportamento e Cognição: Psicologia Comportamental e Cognitiva da reflexão teórica à diversidade na aplicação (p.251-256). Santo André: ARBytes.

Hubner, M.M., \& Marinotti, M. (2000). Crianças com dificuldades escolares. In E.F.M. Silvares
(Org.). Estudo de caso em psicologia clínica comportamental Infantil 2: Estudos Individuais (p.259-304). Campinas: Papirus.

Marinho, M.L. (2001). Subsídios ao terapeuta para análise e tratamento de problemas de comportamento em crianças: quebrando mitos. In M.L. Marinho \& V.E. Caballo (Orgs.). Psicologia clínica e da saúde (p.3-31). Londrina: UEL.

Marinho, M.L. (2002). Un programa estructurado para el entrenamiento de padres. In V.E. Caballo \& M.A. Simón (Orgs.). Manual de psicología clínica infantil y del adolescente. Trastornos específicos (p.417-443). Madrid: Pirámide.

Marturano, E.M. (1999). Recursos no ambiente familiar e dificuldades de aprendizagem na escola. Psicologia: Teoria e Pesquisa, 15, 135-142.

Skinner, B.F. (1991). Questões recentes na análise comportamental. Campinas: Papirus.

Soares, M.R.Z. (2002). A criança hospitalizada: análise de um programa de atividades preparatórias para o procedimento médico de inalação. Tese de doutorado, Instituto de Psicologia, Universidade de São Paulo.

Souza, S.R. (2000). Aplicação do procedimento de construção de anagramas com pais de crianças com dificuldades escolares. Tese de doutorado, Universidade de São Paulo.

Recebido para publicação em 1 de setembro de 2003 e aceito em 3 de novembro de 2004. 